\title{
Natural killer cells in multiple sclerosis
}

Citation for published version (APA):

Mimpen, M., Smolders, J., Hupperts, R., \& Damoiseaux, J. (2020). Natural killer cells in multiple sclerosis: A review. Immunology Letters, 222, 1-11. https://doi.org/10.1016/j.imlet.2020.02.012

Document status and date:

Published: 01/06/2020

DOI:

10.1016/j.imlet.2020.02.012

Document Version:

Publisher's PDF, also known as Version of record

Document license:
Taverne

\section{Please check the document version of this publication:}

- A submitted manuscript is the version of the article upon submission and before peer-review. There can be important differences between the submitted version and the official published version of record.

People interested in the research are advised to contact the author for the final version of the publication, or visit the DOI to the publisher's website.

- The final author version and the galley proof are versions of the publication after peer review.

- The final published version features the final layout of the paper including the volume, issue and page numbers.

Link to publication

\footnotetext{
General rights rights.

- You may freely distribute the URL identifying the publication in the public portal. please follow below link for the End User Agreement:

www.umlib.nl/taverne-license

Take down policy

If you believe that this document breaches copyright please contact us at:

repository@maastrichtuniversity.nl

providing details and we will investigate your claim.
}

Copyright and moral rights for the publications made accessible in the public portal are retained by the authors and/or other copyright owners and it is a condition of accessing publications that users recognise and abide by the legal requirements associated with these

- Users may download and print one copy of any publication from the public portal for the purpose of private study or research.

- You may not further distribute the material or use it for any profit-making activity or commercial gain

If the publication is distributed under the terms of Article $25 \mathrm{fa}$ of the Dutch Copyright Act, indicated by the "Taverne" license above, 
Invited Review

\title{
Natural killer cells in multiple sclerosis: A review
}

\author{
Max Mimpen ${ }^{\mathrm{a}}$, Joost Smolders ${ }^{\mathrm{b}, \mathrm{c}}$, Raymond Hupperts ${ }^{\mathrm{a}, \mathrm{d}}$, Jan Damoiseaux ${ }^{\mathrm{e}, *}$ \\ ${ }^{\text {a }}$ School for Mental Health and Neuroscience, University of Maastricht, Maastricht The Netherlands \\ ${ }^{\mathrm{b}}$ Department of Neurology, Erasmus University Medical Center, Rotterdam The Netherlands \\ ${ }^{\mathrm{c}}$ Department of Neuroimmunology, Netherlands Institute for Neuroscience, Amsterdam The Netherlands \\ ${ }^{\mathrm{d}}$ Department of Neurology, Zuyderland Medical Center, Sittard The Netherlands \\ e Central Diagnostic Laboratory, Maastricht University Medical Center, Maastricht The Netherlands
}

\section{A R T I C L E I N F O}

\section{Keywords:}

Multiple sclerosis

NK cell

Vitamin D

Epstein-Barr virus

\begin{abstract}
A B S T R A C T
As the most common non-traumatic disabling disease among adolescents, multiple sclerosis (MS) is a devastating neurological inflammatory disease of the central nervous system. Research has not yet fully elucidated its pathogenesis, but it has shown MS to be a complex, multifactorial disease with many interplaying factors. One of these factors, natural killer (NK) cells, lymphocytes of the innate immune system, have recently gained attention due to the effects of daclizumab therapy, causing an expansion of the immunoregulatory subset of NK cells. Since then, NK cells and their relation to MS have been the focus of research, with many new findings being published in the last decade. In this review, NK cells are pictured as potent cytotoxic killers, as well as unique immuneregulators. Additionally, an overview of our current knowledge regarding NK cells in MS is given. The role of NK cells in MS is reviewed in the context of well-established environmental factors and current disease modifying therapies to gain further understanding of the pathogenesis and treatment options in MS.
\end{abstract}

\section{Introduction}

Multiple sclerosis (MS) is a chronic inflammatory disorder resulting in demyelination and destruction of neurons in the central nervous system (CNS) [1]. In its most common phenotype, the relapsing-remitting (RR) variant ( $\sim 85 \%)$ [2], patients experience periods of neurological disability, like sensory or motor loss of a limb, followed by (sometimes only partial) recovery [3]. Although the exact mechanism of the development and the progression of MS is still unknown, many factors which contribute to its pathophysiology have been identified [4].

The view of MS on an immunological level has expanded and changed greatly over the years. Whilst classically viewed as a T helper-1 (Th-1) cell mediated disease, [5] many cells have since been identified as contributors to the disease. Notably, Th-17 [5,6], CD8 ${ }^{+}$T-cells $[7,8]$ and B-cells $[7,9]$ are now generally considered to be involved in the inflammatory mechanisms of MS and treatments focussed on B-cells have shown positive results [10]. More recently, the natural killer (NK) cell has emerged as a contributor to the disease. NK cells are lymphocytes of the innate immune system that play a pivotal role in the defence against malignancies as well as viral infections. The identification of this new player in the field was mainly due to the treatment with daclizumab, an IL-2 receptor alpha chain (IL-2Ro; CD25) blocking monoclonal antibody that showed positive results in MS, potentially due to its effects on NK cells [11-13].

The dysfunctions in the immune system of MS patients are the result of the interplay between genetic and environmental risk factors. Genome wide association studies have identified a wide array of genetic polymorphisms linked to the immune system as risk-alleles for MS [14]. Environmental factors include vitamin D [15,16], viral infections like Epstein-Barr virus (EBV) [17] and cytomegalovirus (CMV) [18], smoking [19] and adolescent obesity [19,20]. The full effects of vitamin $\mathrm{D}$ on the immune system are not yet fully understood. Increasing evidence points towards a role in maintaining and restoring immune homeostasis and thereby a protective effect in MS [21,22]. This is considered to be important both in the onset of disease as well as in severity and progression [23]. The EBV hypothesis, postulating a dysfunctional or disproportional reaction to EBV infection as the cause for MS, is currently one of the best fitting models for the pathogenesis of MS. The theory classically claims a 'molecular mimicry' model as explanation for the auto-immune reaction. Recently, some other studies have postulated a model where immortalized B-cells, infected with EBV, play a role in priming and activating lymphocytes in tertiary lymphoid follicles in the meninges [24]. Levels of anti-EBV nuclear antigen 1 (anti-EBNA1) and anti-EBV viral capsid antigen (anti-VCA), which are an indication of EBV activity, are also linked to higher MS

\footnotetext{
*Corresponding author at: Central Diagnostic Laboratory, Maastricht University Medical Center, PO box 5800, 6202 AZ, Maastricht, The Netherlands.

E-mail address: jan.damoiseaux@mumc.nl (J. Damoiseaux).
} 

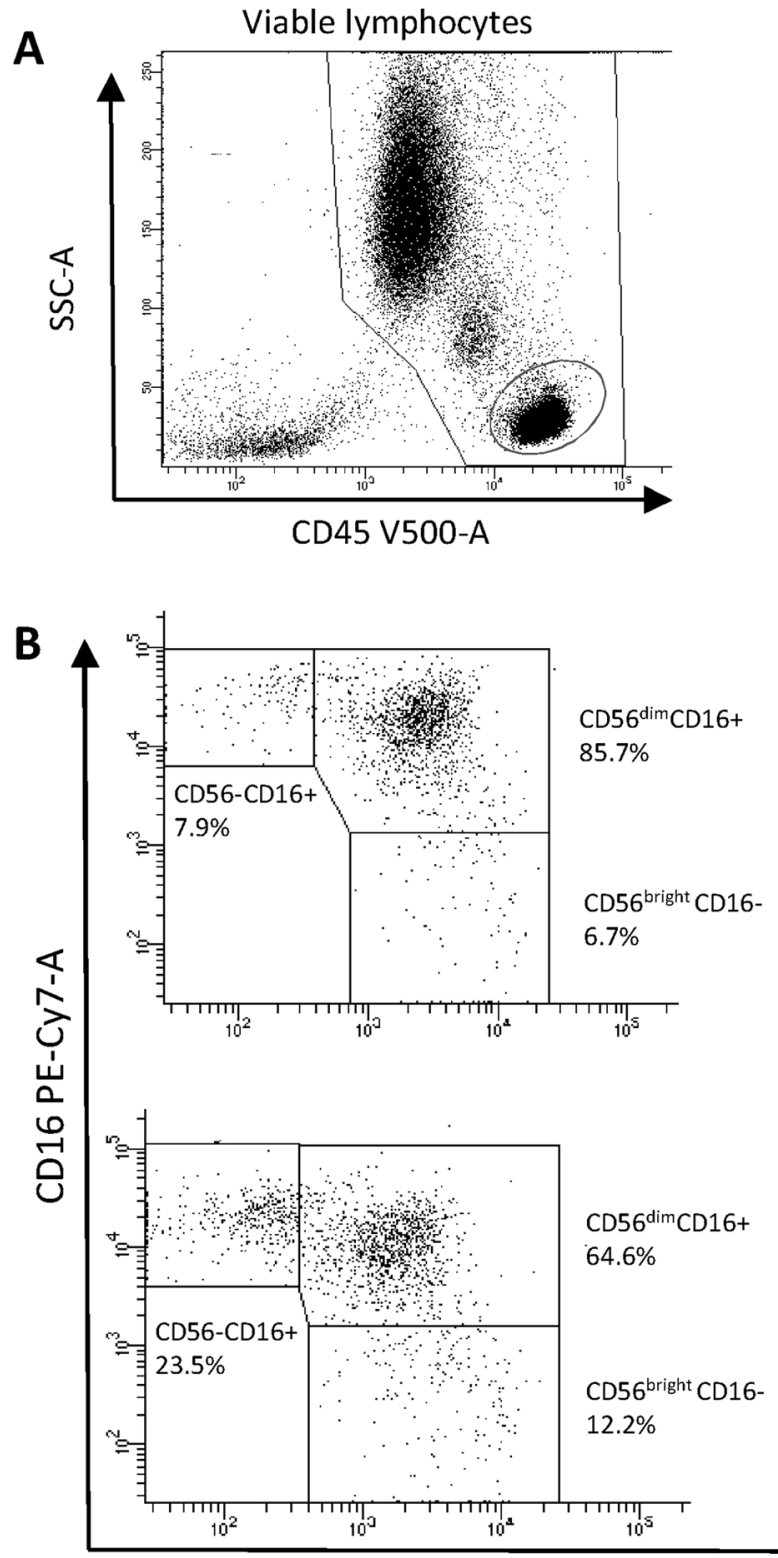
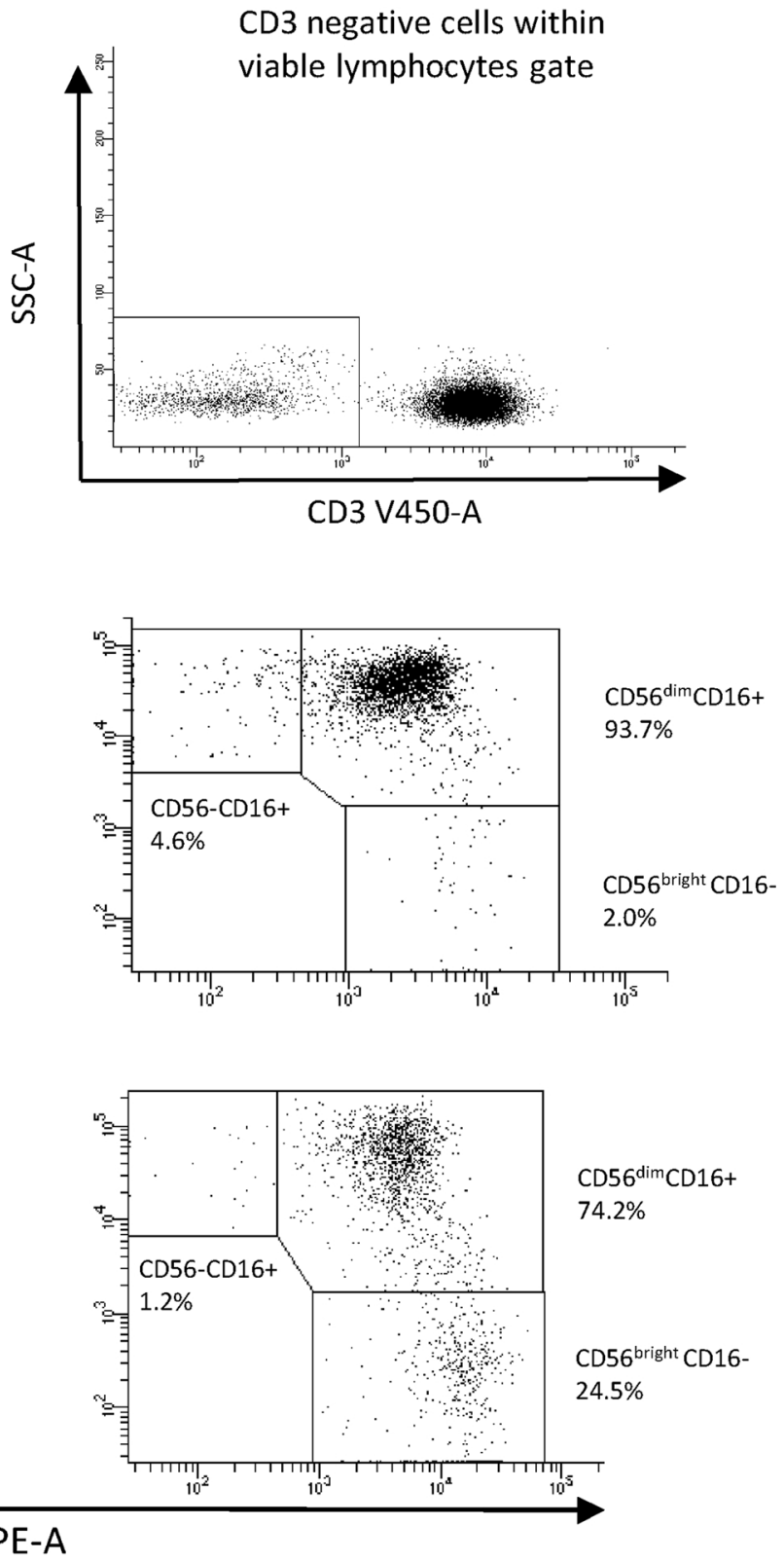

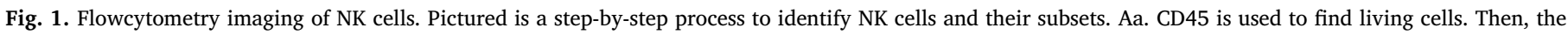

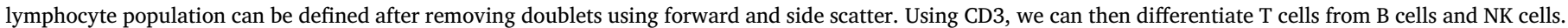

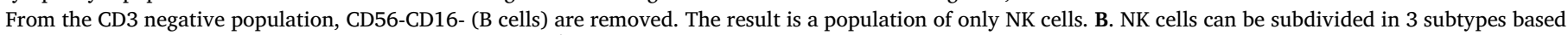

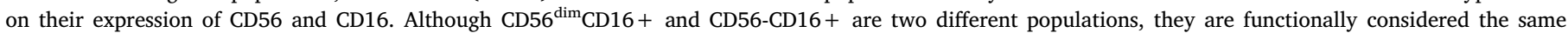

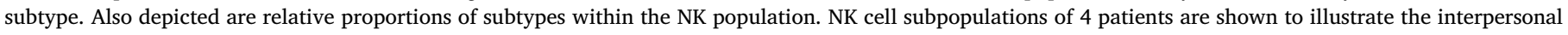
variance in circulating NK cell phenotypes. Cy: cyanin; PE: phycoerythrin; SSC: side scatter.

disease activity [17]. Smoking and obesity are regarded as general inducers of an inflammatory state, thereby potentially contributing to many auto-immune diseases, including MS [19,20].

In this review, the associations between NK cells and MS and its relation with environmental factors are explored. Additionally, the effects of known MS therapies on NK cells are listed.

\section{Natural killer cells}

\subsection{Subsets and functions}

Human NK cells in peripheral blood are phenotypically defined as lymphocytes that lack the expression of CD3, but differentially express CD16 and CD56. Fig. 1 shows a main gating strategy for NK cells from
PBMCs. Circulating NK cells can be divided into a CD56 $6^{\text {bright }}$ and ${ }^{C D 56}{ }^{\text {dim }}$ subset. Some, but not all patients also show a $\mathrm{CD}^{-} 6^{-} \mathrm{CD} 16^{+}$ phenotype, but generally this subset is pooled with the CD56 ${ }^{\mathrm{dim}}$ subset as they seem to fulfil the same role in immunity [25]. Fig. 1 shows 4 different distributions of the NK cell compartment in order to showcase the interindividual variations of NK cells between patients. A further division in NK cell subsets can be made, based on several effector properties of these NK cells. Cichocki et al. divided the NK cell population into 4 subsets, based on their phenotype, i.e., CD56 and CD16, migratory function and memory-like function [26]. The discriminating characteristics of these subsets are further described below.

The circulating CD56 ${ }^{\text {bright }} \mathrm{NK}$ cells are immunoregulatory in nature through their cytokine production in response to chemical signalling [27]. Additionally, CD56 ${ }^{\text {bright }} \mathrm{NK}$ cells produce granzyme K used to kill 
Table 1

Activating and inhibitory human natural killer cell receptors.

\begin{tabular}{|c|c|c|c|c|c|}
\hline Receptor & Risk allele & Ligand & Risk allele & Receptor role & Comments \\
\hline \multicolumn{6}{|l|}{ KIR-family } \\
\hline KIR2DL1 & & HLA-C2 & & Inhibiting & During CNS inflammation, HLA class I (-related) molecules are more abundant due to damaged \\
\hline KIR2DL2/3 & & HLA-C1 & & Inhibiting & cells. The subtype of HLA class I (-related) molecule is dependent on genetic predisposition. \\
\hline KIR2DL4 & & HLA-G & & Activating & \\
\hline KIR2DL5 & & $?$ & & Inhibiting & \\
\hline KIR3DL1 & & HLA-Bw4 & & Inhibiting & \\
\hline KIR3DL2 & & HLA-A3, -A11 & HLA-A & Inhibiting & \\
\hline KIR2DS1 & & HLA-C2 & & Activating & \\
\hline KIR2DS2 & & HLA-C1 & & Activating & \\
\hline KIR2DS3 & & $?$ & & Activating & \\
\hline KIR2DS4 & & $?$ & & Activating & \\
\hline KIR2DS5 & & $?$ & & Activating & \\
\hline KIR3DS1 & & HLA-Bw4 & HLA-B & Activating & \\
\hline \multicolumn{6}{|l|}{ CD94-NKG2 } \\
\hline NKG2A & & HLA-E & & Inhibiting & \\
\hline NKG2C & & HLA-E & & Activating & \\
\hline NKG2E & & HLA-E & & Activating & \\
\hline NKG2D & & $\begin{array}{l}\text { MIC-A/-B, ULBP1/ } \\
2 / 3 / 4\end{array}$ & MIC-A & Activating & \\
\hline \multicolumn{6}{|l|}{ NCRs } \\
\hline NKp30 & & $\begin{array}{l}\text { BAT-3, HSPG, } \\
\text { B7-H6 }\end{array}$ & & Activating & BAT-3 is upregulated in PPMS [54] \\
\hline NKp44 & & Viral HA & & Activating & \\
\hline NKp46 & & Viral HA, HSPG & & Activating & \\
\hline NKp80 & & AICL & & Activating & \\
\hline 2B4 & & $\mathrm{CD} 48$ & $\mathrm{CD} 48$ & Activating & CD48 is upregulated in EAE [49] \\
\hline DNAM-1 & CD226 & PVR, CD112 & PVR & Activating & \\
\hline TIGIT & & PVR, CD112 & PVR & Inhibiting & \\
\hline TACTILE & & PVR, CD112 & PVR & Inhibiting & \\
\hline LILR & & HLA-I, UL18 & & Inhibiting & UL18 is related to CMV infection [52] \\
\hline KLRG1 & & Cadherins & & Inhibiting & Certain cadherins are downregulated during exacerbations [50] \\
\hline Fc $\gamma$ RIII (CD16) & & Antibodies & & Activating & \\
\hline IL-receptors & & $\mathrm{IL}$ & & & \\
\hline IL-1R & & IL-1 & & Inhibitory & IL- $1 \beta$ is found in the blood, CSF and CNS lesions of MS patients [44] \\
\hline IL-2R & IL2RA & IL-2 & & Activating & \\
\hline IL-7R & IL7R & IL-7 & & Activating & In MS, IL-7 levels are reduced and IL-7R $\alpha$ is increased [56] \\
\hline IL-10R & IL10RB & IL-10 & & Inhibitory & IL-10 protects against TNF-induced relapses in EAE [46] \\
\hline IL-12R & IL12RB1 & IL-12 & $\begin{array}{l}\text { IL12A/ } \\
\text { IL12B }\end{array}$ & Activating & Levels of IL-12 are elevated in progressive MS patients serum [45] \\
\hline IL-15R & IL15RA & IL-15 & & Activating & IL-15 is elevated in serum and CSF of MS patients [53] \\
\hline IL-17R & & IL-17 & & Activating & IL-17 is significantly higher in MS patients [55] \\
\hline IL-18R & & IL-18 & & Activating & IL-18 is increased in serum of MS patients; [51] IL-18R is upregulated in CSF of MS patients [48] \\
\hline IL-21R & & IL-21 & & Activating & IL-21 is correlated with more severe MS disease course [47] \\
\hline
\end{tabular}

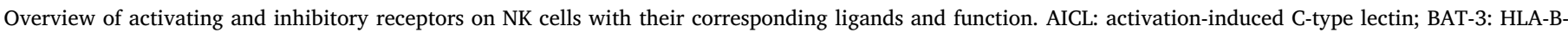

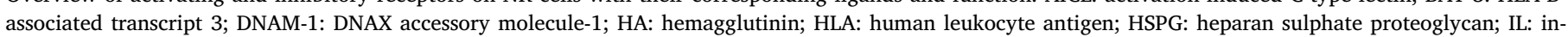

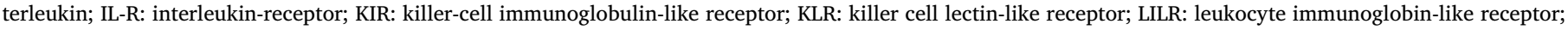

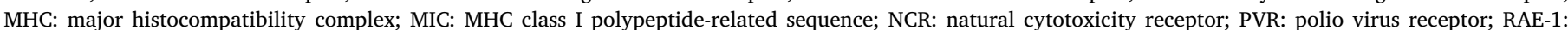

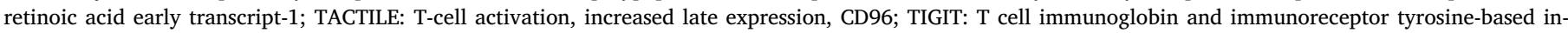

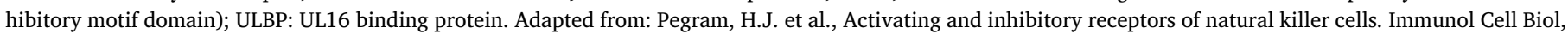
2011. 89(2): p.216-24.

activated CD4 ${ }^{+}$T cells [28]. As CD56 ${ }^{\text {bright }}$ NK cells do not express receptors of the killer-cell immunoglobulin-like receptor (KIR) family, they are less prone to activation by cell-to-cell contact, but more sensitive to cytokine signalling by receptors like the IL-2R or IL-15R. In fact, CD56 ${ }^{\text {bright }}$ NK cells express high levels of the IL-2R, both as medium affinity (IL-2R $\beta \gamma$ ) and high affinity (IL-2R $\alpha \beta \gamma$ ) receptors [29], ensuring its activity and survival in an environment with relatively low IL-2 levels. The cytokines produced by NK cells depend on the manner of activation of the cell. Co-stimulation of IL-12 and IL-18 efficiently induces production of IFN- $\gamma$, but not IL-10. On the other hand, IL-10 is produced upon stimulation of IL-12 together with IL-15 or IL-2 [30]. This specific reaction to different cytokine mixtures, combined with a sensitivity to many chemokines, makes the CD56 ${ }^{\text {bright }} \mathrm{NK}$ cell a potent immunoregulatory cell which could play a protective role in auto-immunity.

Canonical CD56 ${ }^{\mathrm{dim}}$ NK cells are the most abundant in peripheral blood and the most well-known subtype. These cells fulfil a role of immune-surveillance, in that they 'scan' cells for infection or malignant activity. Once a CD56 ${ }^{\mathrm{dim}} \mathrm{NK}$ cell is activated by a relative abundance of activating receptor stimulation, it utilises granzyme B and perforin to induce apoptosis in the target cell. The CD56 ${ }^{\mathrm{dim}} \mathrm{NK}$ cell also releases IFN- $\gamma$ in response to 'finding' an unhealthy cell, thereby creating a proinflammatory environment to further combat the infection or malignant tumour [31]. This pro-inflammatory environment could contribute to the deterioration of auto-immune diseases, like exacerbations in MS, by triggering a re-activation of the (auto-)immune response. CD56 ${ }^{\mathrm{dim}} \mathrm{NK}$ cells also express CD16 (Fc $\gamma$ RIII) which allows the NK cell to sense antibody coated cells and eliminate them through antibody dependent cellular cytotoxicity (ADCC), giving the CD56 ${ }^{\mathrm{dim}}$ NK cells another potent mechanism of eliminating potential threats. It is important to note that, while CD56 ${ }^{\text {bright }}$ cells are primarily considered as cytokine producers and CD56 ${ }^{\mathrm{dim}}$ cells as cytotoxic cells, both subtypes are capable of utilizing both mechanisms. The main difference between the subsets is not their mechanisms of action, but rather the means of activation, as CD56 $6^{\text {bright }}$ cells respond to soluble signalling, while CD56 ${ }^{\text {dim }}$ cells respond to cell-to-cell signalling. 
The concept of a 'memory' CD56 ${ }^{\mathrm{dim}}$ NK cell has been controversial, as memory is considered to be a defining and exclusive feature of the adaptive immune system. However, research in murine models from O'Leary et al. [32] demonstrated that NK cells can, in absence of T- and B-cells, mediate a contact hypersensitivity response, typical of a memory-mediated delayed reaction. Later, Cooper et al. [33] demonstrated that previously activated murine NK cells responded more robustly to stimulation by cytokines. Additionally, when transferring these activated NK cells to naïve donors, they started proliferating whilst maintaining their sensitivity to stimulation. This finding was supported by Sun et al. [34], who demonstrated a rapid expansion of murine NK cells bearing the Ly49H receptor, which specifically recognizes murine cytomegalovirus (CMV), after infection with MCMV. Again, transferring these NK cells to naïve mice and introducing a viral challenge resulted in a far more robust NK cell response and protective immunity. This memory-like phenomenon can also be found in human NK cells. Within the innate immune system, this memory-like process is called 'trained immunity' [35]. These memory-like NK cells are typically found in people infected with human CMV [36] and have several characterising properties. For one, an upregulation of the inhibitory NKG2C receptor was found, together with a downregulation of the FceRI gamma chain adaptor, which is coupled to CD16 [36,37]. The subsequent replacement of the $\gamma$ chain with the $\zeta$ chain is thought to enhance antibody-dependent NK cell activation [38,39]. As such, this subset seems to be less potent in its surveillance role, but far more potent in its antibody dependant role, particularly in cytokine production, compared to regular NK cells [40]. Another characteristic of memory-like NK cells includes the epigenetic silencing of promyelocytic leukemia zinc finger (PLZF) transcription factor, with a currently unknown consequence for the NK cell function [36,37]. The relation between MS and these memory-like NK cells has been investigated [41], but more research is necessary to gain a full understanding of the role memory-like NK cells may have in the inflammatory process of MS.

Tissue-resident NK cells are characterised by a lack of migratory receptors and thus a limited capacity to enter the blood stream. Tissueresident NK cells have been found in the liver, spleen and uterus, each with different phenotypes [42], To the best of our knowledge, no study investigating a CNS specific NK cell subset has been performed. However, since tissue-resident NK cells are thought to play a role in immune homeostasis [43], a disturbance in this subset, even if not localized within the CNS, may alter the intrathecal immune response, thus affecting the course of MS. Obviously, since this remains mere speculation, research into this NK cell subset is warranted to elucidate its potential role in MS.

\subsection{Activation and inhibition}

As stated earlier, both CD56 $6^{\text {bright }}$ and CD56 ${ }^{\mathrm{dim}}$ NK cells rely on a complex system of activation versus inhibition in order to fulfil their effector function. Many activating receptors and inhibitory receptors and their ligands have been identified, as listed in Table 1. [44-56] Table 1 also lists if the gene coding for the receptor/ligand has come up in GWAS studies, as well as their known up-/downregulation in MS.

For activating receptors, several have been extensively studied and their mechanism of action is relatively well known. Prime examples are natural killer gene 2D (NKG2D, CD314), 2B4 (CD244), the natural cytotoxicity receptors (NCR) NKp30, NKp44 and NKp46, and DNAM-1 (DNAX accessory molecule-1). While these receptors can be potent in activating NK cells, a combination of activating signals, like NKp46 with NKG2D, is always required in order to initiate activation [57]. This most likely constitutes a fail-safe mechanism to ensure NK cells do not kill healthy cells. Only signalling through CD16 can independently activate an NK cell. In this case, the specificity of the response is determined through B-cell activity, i.e., antibody production, thus providing a reason why no co-stimulation is needed when circulating NK cells are activated through CD16.
Inhibitory receptors are less abundant than their activating counterparts, but play a more dominant role in the triggering of the NK cell [57]. Inhibitory receptors include members of the KIR family, as well as NKG2A, CD96 (TACTILE) and T-cell immunoreceptor with Ig and ITIM domains (TIGIT). The latter two are paired receptors with the activating DNAM-1 receptor. Interestingly, although many variations of KIR have been identified, a single NK cell expresses only a few [58]. This random selection of inhibiting receptors seems a way for NK cells to better detect different phenotypes of infected/tumour cells. KIR recognise self HLA-A, -B and -C molecules, while NKG2A recognises the less variable HLA-E molecules [59]. TIGIT, like DNAM-1, binds polio virus receptor (PVR) and nectin-2. When one of these inhibitory receptors is engaged, it seems that the activating signalling pathway is blocked, thus preventing the NK cell from initiating its effector function [60]. Even here, it seems that some signals are stronger than others, as it has been shown that NKG2D dependent signalling is easier to inhibit than ADCC signalling via CD16 [61]. Inhibitory receptors also seem to be involved in the 'licensing' of NK cells. This detailed mechanism is reviewed elsewhere [57] and is beyond the scope of this review.

\section{Multiple sclerosis}

\subsection{Disease characteristics}

MS is the most common non-traumatic disabling disease to affect young adults [62]. Its prevalence varies greatly, between 2 in 100.000 in Japan and greater than 200 in 100.000 in Northern Europe and North America [2], with its prevalence increasing with latitude [63]. There is also a gender bias, since women are more often affected compared to men $(3: 1)$ [64,65]. MS is most frequently diagnosed between the ages of 25-40, where a patient can present with a clinically isolated syndrome (CIS). This constitutes a mono- or poly-symptomatic event (depending on its corresponding lesion in the CNS) which develops acutely or subacutely and remains for at least $24 \mathrm{~h}$ [66]. Afterwards there may be a period of recovery, although this is not guaranteed. Typical first presentations include a unilateral optic neuritis (ON), partial myelopathy, focal supratentorial syndrome or focal brainstem or cerebellar syndrome [67]. Frequent symptoms in definite MS include fatigue, reduced walking range, paraesthesia, hypaesthesia, muscle weakness and imbalance [68]. An important diagnostic tool in MS is magnetic resonance imaging (MRI) of the CNS, where typical T2-hyperintense areas may be found around the ventricles (paraventricular), directly adjacent to the cortex (juxtacortical), in the cortex (cortical), infra-tentorial (brainstem/cerebellum) and in the spinal cord. The addition of gadolinium contrast may show contrast enhancement, indicating leakiness of the blood brain barrier due to lymphocyte trafficking. In order to provide a definite MS diagnosis, a dissemination in space (DIS) and dissemination in time (DIT) is required [66]. With a better use of MRI techniques, DIS and DIT are found much earlier and it is no longer required to wait for a second clinical relapse before starting treatment [67]. Additionally, the most recent revisions of the McDonald criteria allow presence of cerebrospinal unique oligoclonal bands to replace the DIT criterion [66]. RRMS is the most prevalent subtype of MS and the focus of almost all disease modifying therapies (DMTs) [2]. For most of these patients (65\% of all RRMS patients [69]), the disease later evolves into a steadily progressing variant, where relapses are replaced by gradual deterioration of the clinical condition. In more contemporary cohorts treated early with disease modifying therapies, a lower estimate of 15-30\% secondary progression has been reported [70]. This secondary progressive MS (SPMS) variant has a less diverse repertoire of treatment options, with currently only interferon-beta being approved for active SPMS treatment [71]. Additionally, an upcoming drug named siponimod is showing promising results in treatment of SPMS patients, reducing their rate of deterioration significantly [72]. Patients may also present with gradually progressive neurological deterioration, without ever experiencing relapses. These patients suffer 
from a primary progressive MS (PPMS) and currently, only ocrelizumab (anti-CD20) is approved for treatment of PPMS [73]. This division into different subtypes is becoming increasingly controversial, as research shows little genetic and clinical distinguishing properties between the subtypes [74]. A more recent classification categorises MS as either relapsing-remitting or progressive. Progressive MS could then be characterized by both 'activity' and 'progression' [75]. Activity is described as the presence of clinical exacerbations, together with MRI findings. These are also the most common endpoints used in intervention trials for RRMS and are frequently reported as a measure of effectiveness of the drug. 'Progression' is monitored through yearly measurement of the expanded disability status scale [76] and implies a loss of function, regardless of new MRI lesions or exacerbations.

\subsection{Natural Killer cells in multiple sclerosis}

The role of NK cells in MS has been a controversial topic, with studies reporting both a protective and a damaging role in MS and experimental auto-immune encephalomyelitis (EAE, the induced variant of MS in animals, usually mice) [77-79]. Much of the exploratory research into NK cells is based on EAE models. Unfortunately, as murine NK cells do not express CD56 and express different receptors, the results of EAE studies are not easily extrapolated to human patients. There are, however, some similarities between murine and human NK cells. The murine NK cell population can be subdivided into $\mathrm{CD} 27^{\text {high }}$ and $\mathrm{CD} 27^{\text {low/ } /-}$, considered to be the equivalent of the human CD56 $6^{\text {bright }}$ and $\mathrm{CD}_{5} 6^{\mathrm{dim}} \mathrm{NK}$ population, respectively [80]. EAE is also different from MS in some aspects. For example, EAE is induced by immunisation with myelin peptides like myelin basic protein [81], even though the exact target or mechanism of auto-inflammation is unknown in MS. These differences can cause discrepancies between murine and human studies. Considering the difficulty of finding patients with MS before clinical manifestation and subsequent lack of understanding of MS pathogenesis, EAE is an excellent model to study the early, pre-clinical stage of MS. For example, one EAE study performed in mice found that in the pre-clinical stage of EAE, the murine NK cell compartment undergoes several changes. For one, The proportion CD27 low/- NK cells increased. Additionally, the receptors of the (immunoregulatory) CD27 ${ }^{\text {high }}$ NK cell population shifted towards a more inhibitory phenotype, including downregulation of the activating Ly49D, Ly49H and NKG2D receptors [82]. Increasing our knowledge of immunological changes leading to clinical disease could increase our insight in MS pathogenesis and provide new therapeutic targets.

Enhancing the regulatory features of NK cells ameliorates the course of EAE. When blocking NKG2A and Qa-1 (the murine equivalent of HLA-E), NK cells inhibited CNS inflammation by killing T cells and microglial cells $[83,84]$. On the other hand, recent research shows that NK cells in MS may also contribute to CNS damage. According to Liu et al., in MS and EAE, NK cells are in contact with neural stem cells (NSCs) and, in EAE, NSCs release IL-15 upon contact with NK cells [85]. IL-15 in turn supports proliferation and survival of NK cells, thus contributing to a stronger NK cell response. However, particularly during the later stages of EAE, NK cells kill NSCs, mainly due to reduced expression of Qa-1. Removing NK cells during the later phases of EAE indeed ameliorated the disease severity [85]. Liu et al. did not determine which subset of NK cells was responsible for these observations. Other studies show that the NK cell population in the CNS and CSF consists mainly of CD56 $6^{\text {bright }}$ NK cells $[86,87]$. This is true for MS patients, but also healthy controls and patients with other neurological disorders, which points towards a location specific enrichment of CD56 ${ }^{\text {bright }}$ NK cells rather than a MS specific phenomenon [88]. This might be related to the higher migratory capacity past the blood brain barrier (BBB) of CD56 $6^{\text {bright }}$ NK cells compared to CD56 ${ }^{\text {dim }}$ NK cells [89]. Even though CD56 $6^{\text {bright }}$ NK cells are abundant in the CNS and CSF, this does not mean that they are responsible for the destructive findings as described by Liu et al. A post-mortem study shows that NK cells most likely damage the myelin in an antibody dependent mechanism, i.e., ADCC, suggesting that CD56 ${ }^{\mathrm{dim}} \mathrm{NK}$ cells are responsible for the damage to the CNS [90]. More research is necessary to fully elucidate the mechanisms of action of both NK cell subsets in MS.

Given their immunoregulatory properties, CD56 ${ }^{\text {bright }}$ NK cells have been monitored in untreated MS patients, patients with clinically isolated syndrome (CIS) suggestive of MS, and healthy controls [91]. Interestingly, the number of CD56 ${ }^{\text {bright }} \mathrm{NK}$ cells in peripheral blood is similar between MS patients and healthy controls. However, when stimulated with cytokines, the CD56 ${ }^{\text {bright }}$ population in MS patients was less efficient in killing activated T-cells than in healthy controls. This difference in efficiency was attributed to an increased expression of HLA-E on T-cells, thus providing more ligand for NKG2A, which acts as an inhibitory receptor on NK cells [91,92]. HLA-E is also found to be upregulated in MS patients in white matter lesions, endothelial cells and astrocytes [93]. Immune cells and neural cells in MS plaques also express higher levels of HLA-E [92]. This would imply that the reason for the weakened response is not a dysfunctional NK cell population, but rather a resistance of target cells towards NK cells due to HLA-E upregulation in MS.

The largest breakthrough for NK cells in MS came with the introduction of daclizumab [94]. This anti-CD25 antibody effectively blocks the $\alpha$-component of the IL- $2 \mathrm{R}$, which is needed to turn a medium affinity IL-2R into a high-affinity IL-2R [95]. The intended mechanism of action of daclizumab was to inhibit T-cell activation, since these Tcells express the high-affinity IL-2R and require IL-2 for activation/ survival [96]. An MS risk-allele can be found in the IL2RA gene (coding for CD25), thus supporting the theory of its involvement in MS [97]. Additionally, this IL2RA gene seems to be influenced by vitamin D in Tcells, thus providing another connection with known MS risk factors $[98,99]$. Early results showed positive outcomes using daclizumab in MS [89,100,101], but paradoxically later studies revealed that blocking IL-2R actually enhanced the T-cell response in vitro, instead of dampening it [102,103]. Additionally, blocking IL-2R meant that regulatory T-cells (Tregs), which normally suppress the immune response, were also inhibited. As such, blocking IL-2R seemed to be more pro- than anti-inflammatory by inducing T-cell immunity and dampening immune regulation by Tregs. Another mechanism of action was sought to explain the beneficial effect of daclizumab, which was found in the expansion of the $\mathrm{CD} 56^{\text {bright }} \mathrm{NK}$ cell population, expressing the mediumaffinity IL-2R. Because of the relative abundance of IL-2 due to blocking of the high affinity IL-2R, these cells could expand around 400-500\% $[89,102]$. Continuing this line of research, it was later found that CD56 ${ }^{\text {bright }}$ NK cells can kill (autologous) activated T-cells, thereby severely limiting the activity of the T-cell population [28,102]. The expansion of $\mathrm{CD} 56^{\text {bright }} \mathrm{NK}$ cells apparently outweighed the reduction in Treg activity. This finding provided solid support for the immunoregulatory and protective role of CD56 $6^{\text {bright }}$ NK cells in MS. Indeed, one Australian study found an inverse correlation between MRI lesions and CD56 $6^{\text {bright }}$ NK cells [104].

\section{Interaction with risk factors}

Despite many genetic loci being associated with MS, genetic aberrations do not fully account for its pathogenesis and course. Only a fraction of the pathogenesis is explained by genetics (a maximum of 25 $\%$ concordance in twin studies [105]), of which nearly $50 \%$ has been accounted for by recent work by the international MS genetic consortium [97]. Epidemiological data points towards a key role for environmental factors in MS. Of these factors, the ones that are currently the most impactful and best understood are vitamin D, infection with EBV and CMV, smoking and adolescent obesity. Full details on how these factors impact MS are beyond the scope of this review. However, looking at how these environmental factors interact with NK cells and vice versa could provide new insights into MS. As the interplay between the different immunological players and environmental factors is 
becoming increasingly complex, this review focuses mainly on the direct effects of environmental factors on NK cells.

\subsection{Vitamin $D$}

When looking at the distribution of MS patients worldwide, an increase in prevalence is found in increasing latitudes [63,106]. Much of this effect is attributed to diminished sun-exposure in countries with higher latitudes, causing less vitamin D to be synthesised in the skin. Genetic pre-disposition did not seem related, as studies with adolescent migrants show a higher risk of developing MS for migrants who move from lower to higher latitudes. Conversely, adolescent migrants from higher latitudes have a lower chance of developing MS when moving towards lower latitudes [107]. Vitamin D is gained through sun-exposure and nutrition, but requires some activating steps in the body before its active variant can be created [108]. Most studies regarding MS, NK cells and vitamin D have used vitamin $\mathrm{D}_{3}$ (cholecalciferol) supplementation. Usually, vitamin D levels are measured in 25-hydroxyvitamin D (calcifediol) which is the precursor for active vitamin D (1,25-dihydroxyvitamin D or calcitriol). Vitamin D is considered to support immune homeostasis $[109,110]$, mainly through the suppression of pro-inflammatory cytokine production by effector T-cells [111]. Since NK cells can show gene expression for VDR [112], a direct effect of vitamin D is to be expected on NK cells as well. Indeed, treating NK cells with 1,25-dihydroxyvitamin $\mathrm{D}$ in vitro shows an increase in cytotoxicity without altering the proliferation of NK cells [113,114]. Several findings support the notion that vitamin D influences NK cell cytotoxicity. For example, studies including elderly patients show that those with low 1,25-dihydroxyvitamin D levels have higher circulating NK cell numbers, likely as a compensation for a reduced cytotoxic potential per individual NK cell $[115,116]$. Also, patients with chronic renal failure (who cannot produce sufficient 1,25-dihydroxyvitamin D) and vitamin D resistant rickets have an impaired immune response, including a decreased NK cell functionality, which can be restored by cholecalciferol or 1,25-dihydroxyvitamin D supplementation $[117,118]$. It is important to note, however, that adding 1,25-dihydroxyvitamin D in a PBMC culture reduces NK cell cytotoxicity. This has been attributed to the production of prostaglandins by monocytes, which express relatively more VDR and thus respond more strongly to vitamin D. Prostaglandins in turn reduce the effectiveness of NK cells $[119,120]$. As such, it seems more likely that a lack of vitamin D reduces the NK cell cytotoxicity, but an abundance of vitamin D does not cause the NK cell to become 'overactive'. Besides the influence on cytotoxicity, vitamin D seems to also influence other facets of the NK cell. Indeed, Weeres et al. point towards a role for 1,25-dihydroxyvitamin D in the developmental process of NK cells, showing a reduced population and reduced cytotoxicity in vitro, using HSC cultures treated with physiological 1,25-dihydroxyvitamin D levels [121]. They suggest an immunoregulatory role of 1,25-dihydroxyvitamin $\mathrm{D}$ by impacting the early development of NK cells at the level of HSCs, seemingly favouring a development of HSCs into monocytes instead, although they do not report on the effect of 1,25-dihydroxyvitamin D on the differentiation into different NK cell subsets. Another influence of vitamin D is reported by Olson et al., who focussed their research on large granular lymphocyte leukaemia. This rare cancer of the T-cell or NK cell lineage [122] is associated with EBV infection and characterised by hyperactivation of the 'signalling transcription and transduction' (STAT)-1, STAT-3 and STAT-5 pathway, resulting in overproduction of cytokines [123,124]. The group studied the effect of 1,25-dihydroxyvitamin D in vitro on the malignant, hyperactive NK cell functionality and cytokine production and found a decrease in STAT-activation and IFN- $\gamma$ production under stimulation of the VDR, pointing towards a regulatory role for 1,25-dihydroxyvitamin D in NK cells. Despite the many promising results regarding the effects of 1,25-dihydroxyvitamin $\mathrm{D}$, it remains unclear whether the supplementation of 25-hydroxyvitamin D actually alters the NK cell population at any level. As such, future research on this subject should be focussed on the effect of supplementing cholecalciferol in vivo and monitoring possible effects on the NK cell population, NK cell subsets and their cytokine panel in MS patients. Nevertheless, these studies do provide evidence of 1,25-dihydroxyvitamin D interacting with NK cells and may offer new insights into the link between vitamin D and the pathogenesis and course of MS.

\subsection{Viral infections}

EBV is a virus of the Herpes family, which mainly transmits through contact with saliva of infected individuals [125]. EBV infects epithelial cells and B-cells, after which it persists in B-cells for the rest of the individuals life. EBV usually persists asymptomatically in healthy and immune-competent individuals and around $90 \%$ of the worldwide population shows signs of EBV exposure. Generally, EBV infection happens during early childhood and is asymptomatic. However, EBV infection in adolescence/adulthood may manifest as infectious mononucleosis (IM) in 30-40\% of patients, associated with chronic fatigue and lymphadenopathy [126]. Its association with MS is evident when looking at epidemiological studies. Of all MS patients, over $99 \%$ show signs of EBV exposure and a medical history of IM increases the risk of developing MS about two-fold compared to overall EBV exposed individuals [127-129]. Moreover, more recent evidence leads some authors to question if a truly EBV-seronegative MS patient even exists, further implying EBV's crucial role in MS pathogenesis [130,131]. The exact mechanism through which EBV contributes to the pathogenesis of MS remains unclear, although a few hypotheses have been formulated, including molecular mimicry and B-cell immortalisation. In almost every case, a role is reserved for the immortalised EBV-infected B-cell, which would normally be kept under strict control by the healthy immune system [132]. Markers for active EBV infection, such as anti-early antigen (anti-EA) IgM and IgA, were found in patients with relapses, but not in clinically stable patients [133]. Due to these findings, the authors suggested that disease activity in MS may be related to re-activation of EBV. Interestingly, a role for vitamin D can also be found in the response against EBV, as evidence shows that anti-EBNA-1 antibodies are reduced in patients receiving vitamin $\mathrm{D}_{3}$ supplementation [134]. NK cells may be involved in EBV in multiple ways. Obviously, as major players in the innate viral immunity, NK cells play a role in the early defence against EBV infection. Indeed, an expansion of NK cells is seen in IM, which is correlated to lower viral load levels in some cases [135]. Likewise, depleting NK cells in mice results in failure to control EBV infection [136]. EBV infection even seems to elicit phenotype changes in NK cells, with an upregulation of NKG2A [137,138], but do not promote a memory-like NK cell phenotype [139]. Besides EBV infection, CMV infection also seems to induce a wide array of changes in the immune system, specifically targeting NK and T-cells [140,141]. For example, as mentioned earlier, CMV is of key importance in the formation of NKG2C + memory-like NK cells, which are more potent in their antibody-dependent mechanisms, but are more limited in their surveillance-dependent potency. In MS, CMV seems to play a protective role in its pathogenesis, as CMV seropositivity was associated with a decreased MS risk (OR $=0.73$ ) [18]. The mechanism of protection is not yet fully understood, however, currently the protective effect of CMV is attributed to its immune configurative properties. For example, one theory states that the memory-like NK cells induced by CMV infection are especially potent in fighting viruses of the herpes family, including EBV [41,142].

\subsection{Lifestyle}

Lifestyle factors seem to play a role in the pathogenesis and disease progression of MS. Of these factors, the most prominent ones are smoking [143,144] and adolescent obesity [145-147]. So far, no specific component of tobacco smoke or adipose tissue has been linked to MS. Indeed, oral tobacco (snuff) actually seems protective against MS 
[148]. The effect of smoking on NK cells has not been researched in the context of MS, but general studies regarding smoking and NK cells may provide clues how smoking affects MS specifically. Evidence is mainly found in COPD and lung cancer studies and is somewhat contradicting. Some studies point towards an enhanced NK cell response and promoted expression of IFN- $\gamma$ due to smoking in murine NK cells [149], as well as increased activated circulating NK cells [150]. However, other studies report a lower circulating volume of NK cells due to smoking $[151,152]$, as well as a lower IFN- $\gamma$ and TNF- $\alpha$ expression and reduced cytotoxicity $[153,154]$. Some of these differences may be explained by presentation of data. Studies reporting an increase in NK cells mostly report a higher percentage of NK cells in smokers, which does not equal an absolute increase in NK cells. It could be possible that smoking reduces all lymphocytes, but it reduces other cells more than NK cells, thus increasing the percentage of NK cells in peripheral blood. However, although smoking clearly affects NK cells in multiple ways, no specific connection between alterations in the NK cell population and MS can currently be made. Obesity has been proven to negatively influence the immune response $[155,156]$ and increase the risk of many disorders, including viral infections $[157,158]$. There is also evidence of alterations in the NK cell population as a result of obesity, like reduced cytotoxicity and cytokine production [159-161]. Additionally, the fact that vitamin $\mathrm{D}$ is fat soluble means that obesity directly impacts circulating vitamin D levels and could lead to a vitamin D deficiency. Again, no specific link can be established between MS and the effect of obesity on NK cells. While it is evident that obesity impacts NK cells and MS, a specific mechanistic relation is currently not feasible. However, both smoking and obesity are general inducers of a pro-inflammatory state. As such, seeing as there currently seems to be no mechanistic connection between smoking or obesity and MS, it seems that this shift towards a pro-inflammatory state caused by lifestyle factors simply lowers the threshold for auto-immunity. A combined theory could be formed with the EBV hypothesis, formulating that EBV infection in a pro-inflammatory environment due to smoking and obesity has a higher risk of causing auto-immunity.

\section{Natural killer cells in therapies for multiple sclerosis}

As mentioned earlier, much of our knowledge about the CD56 $6^{\text {bright }}$ NK cell in MS comes from studies regarding daclizumab. Studies regarding the efficacy of daclizumab showed a significant reduction in MRI lesions and clinical progression, with improvements up to $50 \%$ compared to interferon beta-1a treatment $[11-13,100]$. Although the therapeutic effects were evident, serious concerns were raised regarding its safety profile. Hepatotoxicity was noted in the safety trials, causing authorities to restrict the prescription of daclizumab to only patients who did not respond to other treatments. After its approval, several cases of serious inflammatory brain disorders emerged, causing the suspension and recall of the drug [162]. As such, although CD56 ${ }^{\text {bright }} \mathrm{NK}$ cells seem to have a promising protective and therapeutic potential, no DMTs currently focus on the NK cell population. However, although other drugs were not developed with the intent of influencing the NK cell population, they might have an effect there. Several therapies and their effect on NK cells are listed below.

\subsection{Interferon- $\beta-1 b$}

Interferon- $\beta-1 b$ is one of the earliest therapies for MS. It has a plethora of effector mechanisms, including a reduction of MHC class II molecule expression, reduction of T-cell proliferation, lowered IFN- $\beta$ production and reduced expression of adhesion molecules [163]. Interestingly, interferon- $\beta-1 \mathrm{~b}$ also seems to upregulate MHC class I expression in murine neuron models. As MHC class I is the main inhibitory ligand for CD56 ${ }^{\mathrm{dim}} \mathrm{NK}$ cells, it could be postulated that part of interferon- $\beta-1 b$ 's immunoregulatory effect is due to reduction of cytotoxicity of the $\mathrm{CD} 56^{\mathrm{dim}} \mathrm{NK}$ cell population. Additionally, interferon- $\beta$ -
$1 \mathrm{~b}$ seems to alter the CD56 $6^{\text {bright }} / \mathrm{CD} 56^{\mathrm{dim}} \mathrm{NK}$ cell ratio by expanding the CD56 ${ }^{\text {bright }}$ population in peripheral blood [164], as well as altering the phenotype of the NK cell [165]. This phenotype change consisted of a downregulation of the inhibitory LILRB1 receptor (which binds MHC-I class molecules) and an upregulation of the inhibitory NKG2A receptor (which binds MHC class-I antigen E). Thus, it does not seem to alter the overall inhibition or activation of the NK cell, but rather the method of inhibition. The exact mechanism by which interferon- $\beta-1 \mathrm{~b}$ facilitates the expansion of CD56 ${ }^{\text {bright }} \mathrm{NK}$ cells is unclear, but theories include a mobilisation from the lymph nodes to the peripheral blood. Although interferon- $\beta-1 \mathrm{~b}$ is proven to be effective in slowing disease progression and reducing clinical events, newer drugs are far more potent and have a better prognosis, resulting in a decline of popularity for interferon- $\beta$ $1 b$.

\subsection{Natalizumab}

Natalizumab blocks very late antigen-4 (VLA-4), also known as $\alpha 4 \beta 1$-integrin, a receptor which is crucial in the migration of immune cells between tissues. VLA-4 binds with its counter-receptor, vascular cell adhesion molecule (VCAM)- 1 to facilitate cell migration into the CNS. Natalizumabs intended mechanism of action was to block VLA-4 on T-cells and monocytes so they would be unable to migrate into the CNS and thus be unable to exert their inflammatory effects there. Interestingly, circulating NK cells are increased with natalizumab use $[166,167]$, possibly reflecting a reduced capacity to migrate towards tissues, including the CNS. Indeed, NK cells also express VLA-4 and seem to prefer using a VLA-4 dependent mechanism to migrate into the CNS [89]. As mentioned earlier in this review, NK cells in the CSF are mainly of the CD56 $6^{\text {bright }}$ phenotype. Therefore, as CD56 ${ }^{\text {bright }} \mathrm{NK}$ cells are generally considered as immunoprotective in MS, it would seem that natalizumab exerts both positive and negative effects on the immunological composition of the CNS. Supported by natalizumabs positive outcomes [168-170], the lack of T-cells in the CNS seems to outweigh the reduction of CD56 ${ }^{\text {bright }}$ NK cells.

\subsection{Glatiramer acetate}

Glatiramer acetate (GA) is a drug derived from four amino acids common in MBP (Glu, Ala, Lys, Tyr). It was originally designed as a synthetic antigen capable of inducing EAE. However an opposite effect was found where GA actually protected against EAE instead of inducing it [171]. The main mechanism of action seemed to be based on a shift from Th- 1 cells to Th- 2 cells and activation of Tregs [172,173]. It was demonstrated that monocytes under GA are less responsive to pro-inflammatory stimuli, secrete higher amounts of anti-inflammatory cytokine IL-10 and secrete lower amounts of the pro-inflammatory IL-12 [174]. There also seems to be a role for NK cells in this shift towards Th2 cells. In vitro experiments show that GA enhances the cytolysis of NK cells against both immature and mature DCs, which are implied in the activation of Th-1 cells $[175,176]$. Killing immature DCs is part of the physiological repertoire of the NK cell and GA seems to amplify this by enhancing the interaction between NK cytotoxicity receptors and immature DCs [176]. Killing mature DCs is not a physiological mechanism of the NK cell, but seems to be caused by GA's ability to reduce MHC class I expression on DCs [176]. Thus, less inhibitory signals are received by the NK cells which causes it to kill the DCs. Furthermore, GA decreases the IFN- $\gamma$ production of NK cells, but slightly increases the TNF- $\alpha$ production [176]. In stimulating cytotoxicity against both immature and mature DCs, GA ensures that Th- 1 cells are not activated by antigen presentation. As such, it seems that NK cells are not directly enhanced or altered by GA, but they may be key players in clearing GAaltered DCs. 


\subsection{Dimethyl fumarate}

Dimethyl fumarate (DMF) is a drug which alters many different immune cell populations, although its exact mechanisms are not fully elucidated. DMFs active metabolite, monomethyl fumarate (MMF), is proven to downregulate $\mathrm{T}$ - and $\mathrm{B}$-cell responses through various mechanisms, such as induction of apoptosis, stimulation of Tregs and inhibition of migration to injured tissues [177]. Although the main focus of research has been the adaptive immune system, more recent evidence points towards an effect on the innate immune system as well. More specifically, a marked expansion of the $\mathrm{CD}^{2} 6^{\text {bright }}$ population is noted in patients treated with DMF [178-180]. Additionally, an increase in NK cell degranulation is reported [180]. Seeing as DMF seems to influence nearly every part of the immune system [177], it seems unlikely that the CD56 $6^{\text {bright }}$ NK cell expansion is the sole cause of the immunoprotective effect of DMF. However, it seems likely that the CD56 ${ }^{\text {bright }}$ population plays a role in the beneficial effects of DMF.

\subsection{Fingolimod}

Fingolimod (FTY720) is a sphingosine-1-phosphate (S1P) antagonist, with an intended effect of retaining autoreactive lymphocytes within the lymph nodes $[181,182]$. Its phosphorylated form binds to four of the five $\mathrm{S} 1 \mathrm{P}$ receptors $\left(\mathrm{S}_{1} \mathrm{PR}_{1,3,4,5}\right)$, used in the egress of lymphocytes from the lymph nodes, with $\mathrm{S}_{1} \mathrm{PR}_{1}$ being the most crucial for most lymphocytes [183]. Fingolimod causes a lymphopenia due to an accumulation of lymphocytes in the lymph nodes, although NK cells seem less affected than T- and B-cells. This may be due to the expression of $\mathrm{S}_{1} \mathrm{PR}_{5}$ by NK cells, which is less affected by fingolimod than $\mathrm{S}_{1} \mathrm{PR}_{1}$, thus giving NK cells an alternative method of egressing from lymph nodes. It should be noted that CD56 ${ }^{\mathrm{dim}}$ NK cells have a relative overexpression of $\mathrm{S}_{1} \mathrm{PR}_{5}$, while the $\mathrm{CD} 56^{\text {bright }} \mathrm{NK}$ population expresses relatively more $S 1 \mathrm{PR}_{1}$. Some studies suggest that absolute circulating NK cell numbers do not change under fingolimod treatment [184,185]. Nevertheless, the NK cell population does seem to be affected by fingolimod, as a marked reduction of circulating CD56 ${ }^{\text {bright }} \mathrm{NK}$ cells without a loss of IFN- $\gamma$ and TNF- $\alpha$ production is reported [186]. In the CSF, an expansion of the CD56 ${ }^{\text {bright }}$ subset is noted [187]. As such, it can be postulated that at least some of fingolimods effect is by enriching the $\mathrm{CD} 56^{\text {bright }}$ population in the CSF, thus creating a more immunoprotective environment.

\subsection{Ocrelizumab}

One of the more recent additions to the arsenal of DMTs is ocrelizumab, an anti-CD20 monoclonal antibody developed to deplete the Bcell population. It is quite similar to the more well-known rituximab, another anti-CD20 monoclonal antibody which is used in a variety of auto-immune diseases including neuromyelitis optica, a differential diagnosis of MS [188]. The fact that B-cells are involved in MS is supported by several findings. For one, B-cells are found in MS plaques [189] and in meningeal follicles [190]. Also, one of the diagnostic hallmarks of MS, oligoclonal bands in the CSF, is produced by B-cells [191]. Additionally, as noted earlier, nearly all hypotheses regarding EBV's mechanism of inducing MS involve the infected, immortalized Bcell. As such, there are many ways for the B-cell to potentially influence MS and B-cell depletion seems like a viable method of limiting MS activity. Indeed, its effectiveness is evident from its clinical trials, showing reduced relapse rates and fewer MRI lesions [192,193]. Also, it is currently the only drug to be approved for the treatment of primary progressive MS (PPMS) [194]. Ocrelizumabs intended mechanism is to block a specific epitope of CD20 (which is different than the one bound by rituximab). CD20 is expressed in the majority of B-cell lines, but not stem cells, pro-B cells and plasma cells [195]. Since plasma cells are the main producers of antibodies, antibody levels are not affected by ocrelizumab treatment [196]. Also, a small subset of T-cells $(\sim 6 \%)$ seems to express CD20 [197]. By binding to CD20, ocrelizumab causes the depletion of B-cells mainly by mediating ADCC against the target cell and for a small part by mediating complement dependent cytotoxicity (CDC) and apoptosis [10]. Although CD20 is not expressed on NK cells, they are still involved in ocrelizumabs mechanism since they play a role in ADCC. As such, through the depletion of B-cells, no novel antibodies are produced to coat target cells, which in turn renders the ADCC mechanism of NK cells ineffective.

\section{Conclusions}

Multiple sclerosis is a remarkably complex disease with a multitude of interacting factors contributing to its pathogenesis and course. The relatively recent interest in innate lymphoid cells has revealed new key players in the disease, with NK cells being especially interesting due to their therapeutic potential, as shown in the clinical effect of daclizumab. We reviewed not only the direct relation of NK cells with MS, but also their involvement in the well-known environmental risk factors associated with MS. Additionally, we reviewed the current therapies for RRMS and their effects on NK cells. First, the more specific division of NK cells into four subsets gives rise to new perspectives in how NK cells might influence MS. The characterisation of memory-like NK cells is particularly exciting, as it shows a way for NK cells to easily create a pro-inflammatory environment. As such, this finding might reveal an additional target for therapy. As the concept is relatively new, the role of these memory-like cells must be investigated further to determine their exact role in the pathogenesis of MS and in exacerbations. Another characteristic of NK cells that warrants further investigation is the expression of NK cell receptors. Particularly the changes a NK cell undergoes in response to different infections (e.g., EBV or CMV infection) may play a role in the pathogenesis of MS, suggested by the protective effect of CMV infection. If a change in receptor expression is cause for a faulty immune response causing MS or its exacerbations, therapy blocking or altering the expression of these receptors may prove beneficial. Although NK cells are heavily implicated in MS exacerbations, as shown by Caruana et al. [104], much less clinical evidence exists for a role in the pathogenesis of MS. To explore the early diagnostic potential of NK cells, a study correlating NK cell counts and conversion from CIS to MS is necessary. With MS being a complex, multifactorial disorder, it is imperative to place the NK cell within the context of known environmental risk factors. As NK cells express a VDR, a direct link between NK cells and vitamin D levels can be established. It seems that vitamin D has an immunoregulatory effect on NK cells, thereby contributing to protection against MS. On the other hand, EBV is a known risk factor for MS and might even be a requirement for developing the disease. NK cells are the first line of defence against viruses and EBV seems to alter the NK cell phenotype. Smoking and obesity also contribute to the development of MS, but seem to do so in a non-specific way by stimulating a pro-inflammatory environment. Although no current DMTs specifically target NK cells, some therapies do influence the NK cell population. Mostly, this seems to consist of an increase in CD56 $6^{\text {bright }} \mathrm{NK}$ cells, although none increase the CD56 $6^{\text {bright }}$ population as much as daclizumab did. Considering the undeniable therapeutic effects of daclizumab, the line of CD56 $6^{\text {bright }} \mathrm{NK}$ cell enhancement as a therapy should be explored further, despite the initial setback of daclizumabs hazard profile. In conclusion, NK cells are established as key players in MS. The more we learn about the way they influence the disease, the more we can look towards using NK cells as a diagnostic or safe therapeutic tool in combating MS.

\section{Statement of interests}

MM has nothing to disclose; JS received lecture and/or consultancy fees of Biogen, Merck, Sanofi-Genzyme, and Novartis; RH received institutional research grants and fees for lectures and advisory boards from Biogen, Merck, and Genzyme-Sanofi; JD has nothing to disclose. 


\section{Declaration of Competing Interest}

The authors declare that they have no conflict of interest.

\section{Acknowledgments}

This research did not receive any specific grant from funding agencies in the public, commercial, or not-for-profit sectors.

\section{Appendix A. Supplementary data}

Supplementary material related to this article can be found, in the online version, at doi:https://doi.org/10.1016/j.imlet.2020.02.012.

\section{References}

[1] R. Dobson, G. Giovannoni, Multiple sclerosis - a review, Eur. J. Neurol. 26 (1) (2019) 27-40.

[2] J. Howard, S. Trevick, D.S. Younger, Epidemiology of multiple sclerosis, Neurol. Clin. 34 (4) (2016) 919-939.

[3] L. Steinman, Immunology of relapse and remission in multiple sclerosis, Annu. Rev. Immunol. 32 (2014) 257-281.

[4] D.S. Reich, C.F. Lucchinetti, P.A. Calabresi, Multiple sclerosis, N. Engl. J. Med. 378 (2) (2018) 169-180.

[5] I. Gutcher, B. Becher, APC-derived cytokines and T cell polarization in autoimmune inflammation, J. Clin. Invest. 117 (5) (2007) 1119-1127.

[6] H. Park, et al., A distinct lineage of CD4 T cells regulates tissue inflammation by producing interleukin 17, Nat. Immunol. 6 (11) (2005) 1133-1141.

[7] J. Machado-Santos, et al., The compartmentalized inflammatory response in the multiple sclerosis brain is composed of tissue-resident CD8 + T lymphocytes and B cells, Brain 141 (7) (2018) 2066-2082.

[8] M. Salou, et al., Involvement of CD8(+) t cells in multiple sclerosis, Front. Immunol. 6 (2015) 604.

[9] R. Li, K.R. Patterson, A. Bar-Or, Reassessing B cell contributions in multiple sclerosis, Nat. Immunol. 19 (7) (2018) 696-707.

[10] A.L. Greenfield, S.L. Hauser, B-cell therapy for multiple sclerosis: entering an era, Ann. Neurol. 83 (1) (2018) 13-26.

[11] G. Giovannoni, et al., Daclizumab high-yield process in relapsing-remitting mul tiple sclerosis (SELECTION): a multicentre, randomised, double-blind extension trial, Lancet Neurol. 13 (5) (2014) 472-481.

[12] R. Gold, et al., Daclizumab high-yield process in relapsing-remitting multiple sclerosis (SELECT): a randomised, double-blind, placebo-controlled trial, Lancet 381 (9884) (2013) 2167-2175.

[13] L. Kappos, et al., Daclizumab HYP versus interferon Beta-1a in relapsing multiple sclerosis, N. Engl. J. Med. 373 (15) (2015) 1418-1428.

[14] International Multiple Sclerosis Genetics, C, et al., Analysis of immune-related loci identifies 48 new susceptibility variants for multiple sclerosis, Nat. Genet. 45 (11) (2013) 1353-1360

[15] C. Pierrot-Deseilligny, J.C. Souberbielle, Vitamin D and multiple sclerosis: an update, Mult. Scler. Relat. Disord. 14 (2017) 35-45.

[16] J. Smolders, et al., Vitamin D as an immune modulator in multiple sclerosis, a review, J. Neuroimmunol. 194 (1-2) (2008) 7-17.

[17] Y. Guan, et al., The role of Epstein-Barr virus in multiple sclerosis: from molecular pathophysiology to in vivo imaging, Neural Regen. Res. 14 (3) (2019) 373-386.

[18] E. Sundqvist, et al., Cytomegalovirus seropositivity is negatively associated with multiple sclerosis, Mult. Scler. 20 (2) (2014) 165-173.

[19] L. Alfredsson, T. Olsson, Lifestyle and environmental factors in multiple sclerosis, Cold Spring Harb. Perspect. Med. 9 (4) (2019).

[20] A. Ascherio, Environmental factors in multiple sclerosis, Expert Rev. Neurother. 13 (12 Suppl) (2013) 3-9.

[21] K.C. Fitzgerald, et al., Association of vitamin d levels with multiple sclerosis activity and progression in patients receiving interferon Beta-1b, JAMA Neurol. 72 (12) (2015) 1458-1465.

[22] E.M. Mowry, et al., Vitamin D status predicts new brain magnetic resonance imaging activity in multiple sclerosis, Ann. Neurol. 72 (2) (2012) 234-240.

[23] J. Smolders, Vitamin d and multiple sclerosis: correlation, causality, and controversy, Autoimmune Dis. 2011 (2010) 629538.

[24] S. Burnard, J. Lechner-Scott, R.J. Scott, EBV and MS: major cause, minor contribution or red-herring? Mult. Scler. Relat. Disord. 16 (2017) 24-30.

[25] J. Voigt, et al., Proteome analysis of human CD56(neg) NK cells reveals a homogeneous phenotype surprisingly similar to CD56(dim) NK cells, Eur. J. Immunol. 48 (9) (2018) 1456-1469.

[26] F. Cichicki, et al., Diversification and functional specialization of human NK cell subsets, Curr. Top. Microbiol. Immunol. 395 (2016) 63-94.

[27] A. Poli, et al., CD56bright natural killer (NK) cells: an important NK cell subset, Immunology 126 (4) (2009) 458-465.

[28] W. Jiang, et al., Unexpected role for granzyme K in CD56bright NK cell-mediated immunoregulation of multiple sclerosis, J. Immunol. 187 (2) (2011) 781-790.

[29] T.A. Fehniger, et al., CD56bright natural killer cells are present in human lymph nodes and are activated by T cell-derived IL-2: a potential new link between adaptive and innate immunity, Blood 101 (8) (2003) 3052-3057.
[30] T.A. Fehniger, et al., Differential cytokine and chemokine gene expression by human NK cells following activation with IL-18 or IL-15 in combination with IL12: implications for the innate immune response, J. Immunol. 162 (8) (1999) 4511-4520.

[31] M.A. Caligiuri, Human natural killer cells, Blood 112 (3) (2008) 461-469.

[32] J.G. O'Leary, et al., T cell- and B cell-independent adaptive immunity mediated by natural killer cells, Nat. Immunol. 7 (5) (2006) 507-516.

[33] M.A. Cooper, et al., Cytokine-induced memory-like natural killer cells, Proc Nat Acad Sci U S A 106 (6) (2009) 1915-1919.

[34] J.C. Sun, J.N. Beilke, L.L. Lanier, Adaptive immune features of natural killer cells, Nature 457 (7229) (2009) 557-561.

[35] M.G. Netea, J.W. van der Meer, Trained immunity: an ancient way of remembering, Cell Host Microbe 21 (3) (2017) 297-300.

[36] J. Lee, et al., Epigenetic modification and antibody-dependent expansion of memory-like NK cells in human cytomegalovirus-infected individuals, Immunity 42 (3) (2015) 431-442.

[37] H. Schlums, et al., Cytomegalovirus infection drives adaptive epigenetic diversification of NK cells with altered signaling and effector function, Immunity 42 (3) (2015) 443-456.

[38] I. Hwang, et al., Identification of human NK cells that are deficient for signaling adaptor FcRgamma and specialized for antibody-dependent immune functions, Int. Immunol. 24 (12) (2012) 793-802.

[39] T. Zhang, et al., Cutting edge: antibody-dependent memory-like NK cells distinguished by FcRgamma deficiency, J. Immunol. 190 (4) (2013) 1402-1406.

[40] K.H. Kim, et al., Phenotypic and functional analysis of human NK cell subpopulations according to the expression of FcepsilonRIgamma and NKG2C, Front Immunol. 10 (2019) 2865.

[41] A. Moreira, et al., Adaptive features of natural killer cells in multiple sclerosis, Front. Immunol. 10 (2019) 2403.

[42] H. Peng, Z. Tian, Diversity of tissue-resident NK cells, Semin. Immunol. 31 (2017) $3-10$

[43] A.G. Freud, et al., The broad Spectrum of human natural killer cell diversity, Immunity 47 (5) (2017) 820-833.

[44] S.M. Burm, et al., Expression of IL-1beta in rhesus EAE and MS lesions is mainly induced in the CNS itself, J. Neuroinflammation 13 (1) (2016) 138.

[45] M. Comabella, et al., Elevated interleukin-12 in progressive multiple sclerosis correlates with disease activity and is normalized by pulse cyclophosphamide therapy, J. Clin. Invest. 102 (4) (1998) 671-678.

[46] G.M. Crisi, et al., Staphylococcal enterotoxin B and tumor-necrosis factor-alphainduced relapses of experimental allergic encephalomyelitis: protection by transforming growth factor-beta and interleukin-10, Eur. J. Immunol. 25 (11) (1995) 3035-3040.

[47] T. Gharibi, et al., IL-21 and IL-21-producing T cells are involved in multiple sclerosis severity and progression, Immunol. Lett. 216 (2019) 12-20.

[48] A. Gillett, et al., Interleukin 18 receptor 1 expression distinguishes patients with multiple sclerosis, Mult. Scler. 16 (9) (2010) 1056-1065.

[49] S.L. McArdel, et al., Anti-CD48 monoclonal antibody attenuates experimental autoimmune encephalomyelitis by limiting the number of pathogenic CD $4+t$ cells, J. Immunol. 197 (8) (2016) 3038-3048.

[50] A. Minagar, et al., Serum from patients with multiple sclerosis downregulates occludin and VE-cadherin expression in cultured endothelial cells, Mult. Scler. 9 (3) (2003) 235-238.

[51] F. Nicoletti, et al., Increased serum levels of interleukin-18 in patients with multiple sclerosis, Neurology 57 (2) (2001) 342-344.

[52] V. Prod'homme, et al., The human cytomegalovirus MHC class I homolog UL18 inhibits LIR-1 + but activates LIR-1- NK cells, J. Immunol. 178 (7) (2007) 4473-4481.

[53] M. Rentzos, et al., IL-15 is elevated in serum and cerebrospinal fluid of patients with multiple sclerosis, J. Neurol. Sci. 241 (1-2) (2006) 25-29.

[54] M. Saresella, et al., A role for the TIM-3/GAL-9/BAT3 pathway in determining the clinical phenotype of multiple sclerosis, FASEB J. 28 (11) (2014) 5000-5009.

[55] C. Schofield, et al., Characterization of IL-17AA and IL-17FF in rheumatoid arthritis and multiple sclerosis, Bioanalysis 8 (22) (2016) 2317-2327.

[56] N. Su, et al., Interleukin-7 expression and its effect on natural killer cells in patients with multiple sclerosis, J. Neuroimmunol. 276 (1-2) (2014) 180-186.

[57] E.O. Long, et al., Controlling natural killer cell responses: integration of signals for activation and inhibition, Annu. Rev. Immunol. 31 (2013) 227-258.

[58] N.M. Valiante, et al., Functionally and structurally distinct NK cell receptor repertoires in the peripheral blood of two human donors, Immunity 7 (6) (1997) 739-751.

[59] F. Borrego, et al., Recognition of human histocompatibility leukocyte antigen (HLA)-E complexed with HLA class I signal sequence-derived peptides by CD94/ NKG2 confers protection from natural killer cell-mediated lysis, J. Exp. Med. 187 (5) (1998) 813-818.

[60] M. Eriksson, et al., Inhibitory receptors alter natural killer cell interactions with target cells yet allow simultaneous killing of susceptible targets, J. Exp. Med. 190 (7) (1999) 1005-1012

[61] A. Das, E.O. Long, Lytic granule polarization, rather than degranulation, is the preferred target of inhibitory receptors in NK cells, J. Immunol. 185 (8) (2010) 4698-4704.

[62] G. Kobelt, et al., New insights into the burden and costs of multiple sclerosis in Europe, Mult. Scler. 23 (8) (2017) 1123-1136.

[63] P. Browne, et al., Atlas of Multiple Sclerosis 2013: a growing global problem with widespread inequity, Neurology 83 (11) (2014) 1022-1024.

[64] S.M. Orton, et al., Effect of immigration on multiple sclerosis sex ratio in Canada: the Canadian Collaborative Study, J Neurol Neurosurg Psychiatry 81 (1) (2010) 
$31-36$

[65] M.T. Wallin, et al., The Gulf War era multiple sclerosis cohort: age and incidence rates by race, sex and service, Brain 135 (Pt 6) (2012) 1778-1785.

[66] A.J. Thompson, et al., Diagnosis of multiple sclerosis: 2017 revisions of the McDonald criteria, Lancet Neurol. 17 (2) (2018) 162-173.

[67] W.J. Brownlee, et al., Diagnosis of multiple sclerosis: progress and challenges, Lancet 389 (10076) (2017) 1336-1346.

[68] R.J. Fox, et al., Prevalence of multiple sclerosis symptoms across lifespan: data from the NARCOMS Registry, Neurodegener. Dis. Manag. 5 (6 Suppl) (2015) 3-10.

[69] C. Confavreux, S. Vukusic, Age at disability milestones in multiple sclerosis, Brain 129 (Pt 3) (2006) 595-605.

[70] A.J. Thompson, et al., Multiple sclerosis, Lancet 391 (10130) (2018) 1622-1636.

[71] Placebo-controlled multicentre randomised trial of interferon beta-1b in treatment of secondary progressive multiple sclerosis. European Study Group on interferon beta-1b in secondary progressive MS, Lancet 352 (9139) (1998) 1491-1497.

[72] L. Kappos, et al., Siponimod versus placebo in secondary progressive multiple sclerosis (EXPAND): a double-blind, randomised, phase 3 study, Lancet 391 (10127) (2018) 1263-1273.

[73] L.E. Baldassari, R.J. Fox, Therapeutic advances and challenges in the treatment of progressive multiple sclerosis, Drugs 78 (15) (2018) 1549-1566.

[74] H. Lassmann, W. Bruck, C.F. Lucchinetti, The immunopathology of multiple sclerosis: an overview, Brain Pathol. 17 (2) (2007) 210-218.

[75] F.D. Lublin, et al., Defining the clinical course of multiple sclerosis: the 2013 revisions, Neurology 83 (3) (2014) 278-286.

[76] J.F. Kurtzke, Rating neurologic impairment in multiple sclerosis: an expanded disability status scale (EDSS), Neurology 33 (11) (1983) 1444-1452.

[77] R. Gandhi, A. Laroni, H.L. Weiner, Role of the innate immune system in the pathogenesis of multiple sclerosis, J. Neuroimmunol. 221 (1-2) (2010) 7-14.

[78] J.D. Lunemann, C. Munz, Do natural killer cells accelerate or prevent autoimmunity in multiple sclerosis? Brain 131 (Pt 7) (2008) 1681-1683.

[79] B. Morandi, et al., Role of natural killer cells in the pathogenesis and progression of multiple sclerosis, Pharmacol. Res. 57 (1) (2008) 1-5.

[80] Y. Hayakawa, et al., Functional subsets of mouse natural killer cells, Immunol. Rev. 214 (2006) 47-55.

[81] C.S. Constantinescu, et al., Experimental autoimmune encephalomyelitis (EAE) as a model for multiple sclerosis (MS), Br. J. Pharmacol. 164 (4) (2011) 1079-1106.

[82] M. Gao, et al., CD27 natural killer cell subsets play different roles during the preonset stage of experimental autoimmune encephalomyelitis, Innate Immun. 22 (6) (2016) 395-404.

[83] J.W. Leavenworth, et al., Analysis of the cellular mechanism underlying inhibition of EAE after treatment with anti-NKG2A F(ab')2, Proc Natl Acad Sci U S A 107 (6) (2010) 2562-2567.

[84] L. Lu, et al., Regulation of activated CD4 + T cells by NK cells via the Qa-1-NKG2A inhibitory pathway, Immunity 26 (5) (2007) 593-604.

[85] Q. Liu, et al., Neural stem cells sustain natural killer cells that dictate recovery from brain inflammation, Nat. Neurosci. 19 (2) (2016) 243-252.

[86] S. Han, et al., Comprehensive immunophenotyping of cerebrospinal fluid cells in patients with neuroimmunological diseases, J. Immunol. 192 (6) (2014) 2551-2563.

[87] E. Rodriguez-Martin, et al., Natural killer cell subsets in cerebrospinal fluid of patients with multiple sclerosis, Clin. Exp. Immunol, 180 (2) (2015) 243-249.

[88] C.C. Gross, et al., Regulatory functions of natural killer cells in multiple sclerosis, Front. Immunol. 7 (2016) 606.

[89] C.C. Gross, et al., Impaired NK-mediated regulation of T-cell activity in multiple sclerosis is reconstituted by IL-2 receptor modulation, Proc Natl Acad Sci U S A 113 (21) (2016) E2973-82

[90] N. Lagumersindez-Denis, et al., Differential contribution of immune effector mechanisms to cortical demyelination in multiple sclerosis, Acta Neuropathol. 134 (1) (2017) 15-34.

[91] A. Laroni, et al., Dysregulation of regulatory CD56(bright) NK cells/T cells interactions in multiple sclerosis, J. Autoimmun. 72 (2016) 8-18.

[92] F. Morandi, et al., Intrathecal soluble HLA-E correlates with disease activity in patients with multiple sclerosis and may cooperate with soluble HLA-G in the resolution of neuroinflammation, J. Neuroimmune Pharmacol. 8 (4) (2013) 944-955.

[93] K. Pannemans, et al., HLA-E restricted CD8 + T cell subsets are phenotypically altered in multiple sclerosis patients, Mult. Scler. 20 (7) (2014) 790-801.

[94] B. Bielekova, Daclizumab therapy for multiple sclerosis, Cold Spring Harb. Perspect. Med. 9 (5) (2019).

[95] X. Wang, M. Rickert, K.C. Garcia, Structure of the quaternary complex of interleukin-2 with its alpha, beta, and gammac receptors, Science 310 (5751) (2005) $1159-1163$.

[96] T.A. Waldmann, The IL-2/IL-15 receptor systems: targets for immunotherapy, J. Clin. Immunol. 22 (2) (2002) 51-56.

[97] International Multiple Sclerosis Genetics, C, Multiple sclerosis genomic map im plicates peripheral immune cells and microglia in susceptibility, Science 365 (6460) (2019)

[98] T. Berge, et al., The multiple sclerosis susceptibility genes TAGAP and IL2RA are regulated by vitamin D in CD4 + T cells, Genes Immun. 17 (2) (2016) 118-127.

[99] L. Rolf, et al., Vitamin D3 supplementation and the IL-2/IL-2R pathway in multiple sclerosis: attenuation of progressive disturbances? J. Neuroimmunol. 314 (2018) 50-57.

[100] B. Bielekova, et al., Effect of anti-CD25 antibody daclizumab in the inhibition of inflammation and stabilization of disease progression in multiple sclerosis, Arch. Neurol. 66 (4) (2009) 483-489.

[101] B. Bielekova, et al., Humanized anti-CD25 (daclizumab) inhibits disease activity in multiple sclerosis patients failing to respond to interferon beta, Proc Natl Acad Sci U S A 101 (23) (2004) 8705-8708.

[102] B. Bielekova, et al., Regulatory CD56(bright) natural killer cells mediate immunomodulatory effects of IL-2Ralpha-targeted therapy (daclizumab) in multiple sclerosis, Proc Natl Acad Sci U S A 103 (15) (2006) 5941-5946.

[103] J.F. Martin, et al., An IL-2 paradox: blocking CD25 on T cells induces IL-2-driven activation of CD56(bright) NK cells, J. Immunol. 185 (2) (2010) 1311-1320.

[104] P. Caruana, et al., Natural killer cell subpopulations are associated with MRI activity in a relapsing-remitting multiple sclerosis patient cohort from Australia, Mult. Scler. 23 (11) (2017) 1479-1487.

[105] H. Westerlind, et al., Modest familial risks for multiple sclerosis: a registry-based study of the population of Sweden, Brain 137 (Pt 3) (2014) 770-778.

[106] S. Simpson . Jr.et al., Latitude is significantly associated with the prevalence of multiple sclerosis: a meta-analysis, J Neurol Neurosurg Psychiatry 82 (10) (2011) $1132-1141$.

[107] K. Ismailova, et al., Vitamin D in early life and later risk of multiple sclerosis-A systematic review, meta-analysis, PLoS One 14 (8) (2019) e0221645.

[108] D.D. Bikle, Vitamin D metabolism, mechanism of action, and clinical applications, Chem. Biol. 21 (3) (2014) 319-329.

[109] E. Peelen, et al., Effects of vitamin D on the peripheral adaptive immune system: a review, Autoimmun. Rev. 10 (12) (2011) 733-743.

[110] J. Smolders, et al., Vitamin D in the healthy and inflamed central nervous system: access and function, J. Neurol. Sci. 311 (1-2) (2011) 37-43.

[111] J. Smolders, J. Damoiseaux, Vitamin D as a T-cell modulator in multiple sclerosis, Vitam. Horm. 86 (2011) 401-428.

[112] Y. Moran-Auth, et al., Vitamin D status and gene transcription in immune cells, J. Steroid Biochem. Mol. Biol. 136 (2013) 83-85.

[113] G. Balogh, et al., Effect of 1,25(OH)(2)-vitamin D(3) on the activation of natural killer cells: role of protein kinase $C$ and extracellular calcium, Exp. Mol. Pathol. 67 (2) (1999) 63-74.

[114] A. Ravid, et al., 1,25(OH)2D3 increases cytotoxicity and exocytosis in lymphokineactivated killer cells, Mol. Cell. Endocrinol. 96 (1-2) (1993) 133-139.

[115] E. Mariani, et al., Vitamin D, thyroid hormones and muscle mass influence natura killer (NK) innate immunity in healthy nonagenarians and centenarians, Clin. Exp. Immunol. 116 (1) (1999) 19-27.

[116] E. Mariani, et al., Natural immunity and bone and muscle remodelling hormones in the elderly, Mech. Ageing Dev. 102 (2-3) (1998) 279-292.

[117] I. Kitajima, et al., Immune dysfunction in hypophosphatemic vitamin D-resistant rickets: immunoregulatory reaction of 1 alpha( $(\mathrm{OH})$ vitamin D3, Clin. Immunol. Immunopathol. 53 (1) (1989) 24-31.

[118] J.M. Quesada, et al., The effect of calcitriol on natural killer cell activity in hemodialyzed patients, J. Steroid Biochem. 34 (1-6) (1989) 423-425.

[119] F. Merino, et al., Regulation of natural killer cytotoxicity by 1,25-dihydroxyvitamin D3, Cell. Immunol. 118 (2) (1989) 328-336.

[120] C. Rebut-Bonneton, J. Demignon, Effect of calcitriol on peripheral blood lymphocyte cytotoxicity, Biomed. Pharmacother. 45 (8) (1991) 369-372.

[121] M.A. Weeres, et al., The effects of 1,25-dihydroxyvitamin D3 on in vitro human NK cell development from hematopoietic stem cells, J. Immunol. 193 (7) (2014) 3456-3462.

[122] K.C. Olson, et al., Vitamin D pathway activation selectively deactivates signal transducer and activator of transcription (STAT) proteins and inflammatory cytokine production in natural killer leukemic large granular lymphocytes, Cytokine 111 (2018) 551-562

[123] K.C. Olson, et al., Vitamin D decreases STAT phosphorylation and inflammatory cytokine output in T-LGL leukemia, Cancer Biol. Ther. 18 (5) (2017) 290-303.

[124] H.L. Rajala, et al., Uncovering the pathogenesis of large granular lymphocytic leukemia-novel STAT3 and STAT5b mutations, Ann. Med. 46 (3) (2014) 114-122.

[125] Q.Y. Yao, A.B. Rickinson, M.A. Epstein, A re-examination of the Epstein-Barr virus carrier state in healthy seropositive individuals, Int. J. Cancer 35 (1) (1985) $35-42$.

[126] J.I. Cohen, Epstein-Barr virus infection, N. Engl. J. Med. 343 (7) (2000) 481-492.

[127] M.J. Goldacre, et al., Multiple sclerosis after infectious mononucleosis: record linkage study, J. Epidemiol. Community Health 58 (12) (2004) 1032-1035.

[128] A.E. Handel, et al., An updated meta-analysis of risk of multiple sclerosis following infectious mononucleosis, PLoS One 5 (9) (2010).

[129] E. Sundqvist, et al., Epstein-Barr virus and multiple sclerosis: interaction with HLA, Genes Immun. 13 (1) (2012) 14-20.

[130] K. Deuschle, et al., Are there Epstein-Barr virus seronegative patients with multiple sclerosis? Mult. Scler. 19 (9) (2013) 1242-1243.

[131] J. Pakpoor, et al., The risk of developing multiple sclerosis in individuals seronegative for Epstein-Barr virus: a meta-analysis, Mult. Scler. 19 (2) (2013) $162-166$.

[132] D.A. Thorley-Lawson, EBV persistence-Introducing the virus, Curr. Top. Microbiol. Immunol. 390 (Pt 1) (2015) 151-209.

[133] K. Wandinger, et al., Association between clinical disease activity and Epstein-Barr virus reactivation in MS, Neurology 55 (2) (2000) 178-184.

[134] L. Rolf, et al., Exploring the effect of vitamin D3 supplementation on the anti-EBV antibody response in relapsing-remitting multiple sclerosis, Mult. Scler. 24 (10) (2018) 1280-1287.

[135] H. Williams, et al., The immune response to primary EBV infection: a role for natural killer cells, Br. J. Haematol. 129 (2) (2005) 266-274.

[136] O. Chijioke, et al., Human natural killer cells prevent infectious mononucleosis features by targeting lytic Epstein-Barr virus infection, Cell Rep. 5 (6) (2013) $1489-1498$.

[137] T. Azzi, et al., Role for early-differentiated natural killer cells in infectious mononucleosis, Blood 124 (16) (2014) 2533-2543. 
[138] O. Chijioke, V. Landtwing, C. Munz, NK cell influence on the outcome of primary epstein-barr virus infection, Front. Immunol. 7 (2016) 323.

[139] D.W. Hendricks, et al., Cutting edge: NKG2C(hi)CD57 + NK cells respond specifically to acute infection with cytomegalovirus and not Epstein-Barr virus, J. Immunol. 192 (10) (2014) 4492-4496.

[140] P. Brodin, et al., Variation in the human immune system is largely driven by nonheritable influences, Cell 160 (1-2) (2015) 37-47.

[141] G. Picarda, C.A. Benedict, Cytomegalovirus: shape-shifting the immune system, J. Immunol. 200 (12) (2018) 3881-3889.

[142] M. Lopez-Montanes, et al., Antibody-dependent NK cell activation differentially targets EBV-Infected cells in lytic cycle and bystander B lymphocytes bound to viral antigen-containing particles, J. Immunol. 199 (2) (2017) 656-665.

[143] A.K. Hedstrom, et al., Tobacco smoking, but not Swedish snuff use, increases the risk of multiple sclerosis, Neurology 73 (9) (2009) 696-701.

[144] A.K. Hedstrom, T. Olsson, L. Alfredsson, Smoking is a major preventable risk factor for multiple sclerosis, Mult. Scler. 22 (8) (2016) 1021-1026.

[145] A.K. Hedstrom, et al., Interaction between adolescent obesity and HLA risk genes in the etiology of multiple sclerosis, Neurology 82 (10) (2014) 865-872.

[146] A.K. Hedstrom, T. Olsson, L. Alfredsson, Body mass index during adolescence, rather than childhood, is critical in determining MS risk, Mult. Scler. 22 (7) (2016) 878-883.

[147] K.L. Munger, et al., Childhood body mass index and multiple sclerosis risk: a longterm cohort study, Mult. Scler. 19 (10) (2013) 1323-1329.

[148] A.K. Hedstrom, et al., Nicotine might have a protective effect in the etiology of multiple sclerosis, Mult. Scler. 19 (8) (2013) 1009-1013.

[149] G.T. Motz, et al., Chronic cigarette smoke exposure primes NK cell activation in a mouse model of chronic obstructive pulmonary disease, J. Immunol. 184 (8) (2010) 4460-4469.

[150] J. Wang, et al., Differential activation of killer cells in the circulation and the lung: a study of current smoking status and chronic obstructive pulmonary disease (COPD), PLoS One 8 (3) (2013) e58556.

[151] P. Moszczynski, J. Rutowski, S. Slowinski, The effect of cigarettes smoking on the blood counts of $\mathrm{T}$ and NK cells in subjects with occupational exposure to organic solvents, Cent. Eur. J. Public Health 4 (3) (1996) 164-168.

[152] D.J. Tollerud, et al., Association of cigarette smoking with decreased numbers of circulating natural killer cells, Am. Rev. Respir. Dis. 139 (1) (1989) 194-198.

[153] S. Arimilli, B.E. Damratoski, G.L. Prasad, Combustible and non-combustible tobacco product preparations differentially regulate human peripheral blood mononuclear cell functions, Toxicol. In Vitro 27 (6) (2013) 1992-2004.

[154] M.F. Mian, et al., Impairment of human NK cell cytotoxic activity and cytokine release by cigarette smoke, J. Leukoc. Biol. 83 (3) (2008) 774-784.

[155] A. Castoldi, et al., The macrophage switch in obesity development, Front. Immunol. 6 (2015) 637.

[156] V.A. Gerriets, N.J. MacIver, Role of T cells in malnutrition and obesity, Front. Immunol. 5 (2014) 379.

[157] J.K. Louie, et al., A novel risk factor for a novel virus: obesity and 2009 pandemic influenza A (H1N1), Clin. Infect. Dis. 52 (3) (2011) 301-312.

[158] A.G. Smith, et al., Diet-induced obese mice have increased mortality and altere immune responses when infected with influenza virus, J. Nutr. 137 (5) (2007) 1236-1243.

[159] I. Bahr, et al., Diet-induced obesity is associated with an impaired NK cell function and an increased Colon Cancer incidence, J. Nutr. Metab. 2017 (2017) 4297025.

[160] L. Huebner, et al., Human NK cell subset functions are differentially affected by adipokines, PLoS One 8 (9) (2013) e75703.

[161] S. Wilk, et al., Adiponectin modulates NK-cell function, Eur. J. Immunol. 43 (4) (2013) 1024-1033.

[162] L. The, End of the road for daclizumab in multiple sclerosis, Lancet 391 (10125) (2018) 1000

[163] V.W. Yong, Differential mechanisms of action of interferon-beta and glatiramer aetate in MS, Neurology 59 (6) (2002) 802-808.

[164] M. Saraste, H. Irjala, L. Airas, Expansion of CD56Bright natural killer cells in the peripheral blood of multiple sclerosis patients treated with interferon-beta, Neurol. Sci. 28 (3) (2007) 121-126.

[165] J.E. Martinez-Rodriguez, et al., Natural killer cell phenotype and clinical response to interferon-beta therapy in multiple sclerosis, Clin. Immunol. 141 (3) (2011) $348-356$.

[166] M. Kaufmann, et al., Real-world lab data in natalizumab treated multiple sclerosis patients up to 6 years long-term follow up, Front. Neurol. 9 (2018) 1071.

[167] N. Putzki, et al., Effects of natalizumab on circulating B cells, T regulatory cells and natural killer cells, Eur. Neurol. 63 (5) (2010) 311-317.

[168] C.H. Polman, et al., A randomized, placebo-controlled trial of natalizumab for relapsing multiple sclerosis, N. Engl. J. Med. 354 (9) (2006) 899-910.
[169] E.W. Radue, et al., Natalizumab plus interferon beta-1a reduces lesion formation in relapsing multiple sclerosis, J. Neurol. Sci. 292 (1-2) (2010) 28-35.

[170] R.A. Rudick, et al., Natalizumab plus interferon beta-1a for relapsing multiple sclerosis, N. Engl. J. Med. 354 (9) (2006) 911-923.

[171] B. Weinstock-Guttman, et al., Two decades of glatiramer acetate: from initial discovery to the current development of generics, J. Neurol. Sci. 376 (2017) 255-259.

[172] R. Arnon, R. Aharoni, Mechanism of action of glatiramer acetate in multiple sclerosis and its potential for the development of new applications, Proc Natl Acad Sci U S A 101 (Suppl 2) (2004) 14593-14598.

[173] J. Hong, et al., Induction of CD4 + CD25 + regulatory T cells by copolymer-I through activation of transcription factor Foxp3, Proc Natl Acad Sci U S A 102 (18) (2005) 6449-6454.

[174] H.J. Kim, et al., Type 2 monocyte and microglia differentiation mediated by glatiramer acetate therapy in patients with multiple sclerosis, J. Immunol. 172 (11) (2004) 7144-7153.

[175] R.A. Hoglund, et al., A one year follow-up study of natural killer and dendritic cells activities in multiple sclerosis patients receiving glatiramer acetate (GA), PLoS One 8 (4) (2013) e62237.

[176] K.L. Sand, et al., Modulation of natural killer cell cytotoxicity and cytokine release by the drug glatiramer acetate, Cell. Mol. Life Sci. 66 (8) (2009) 1446-1456.

[177] A. Hosseini, et al., Dimethyl fumarate: regulatory effects on the immune system in the treatment of multiple sclerosis, J. Cell. Physiol. 234 (7) (2019) 9943-9955.

[178] D. Marastoni, et al., Increased NK cell count in multiple sclerosis patients treated with dimethyl fumarate: a 2-Year longitudinal study, Front. Immunol. 10 (2019) 1666.

[179] G. Montes Diaz, et al., Dimethyl fumarate induces a persistent change in the composition of the innate and adaptive immune system in multiple sclerosis patients, Sci. Rep. 8 (1) (2018) 8194.

[180] M.D. Smith, P.A. Calabresi, P. Bhargava, Dimethyl fumarate treatment alters NK cell function in multiple sclerosis, Eur. J. Immunol. 48 (2) (2018) 380-383.

[181] J.A. Cohen, et al., Oral fingolimod or intramuscular interferon for relapsing multiple sclerosis, N. Engl. J. Med. 362 (5) (2010) 402-415.

[182] L. Kappos, et al., A placebo-controlled trial of oral fingolimod in relapsing multiple sclerosis, N. Engl. J. Med. 362 (5) (2010) 387-401.

[183] J.G. Cyster, S.R. Schwab, Sphingosine-1-phosphate and lymphocyte egress from lymphoid organs, Annu. Rev. Immunol. 30 (2012) 69-94.

[184] M. Kaufmann, et al., Real world lab data: patterns of lymphocyte counts in fingolimod treated patients, Front. Immunol. 9 (2018) 2669

[185] L.M. Vaessen, et al., FTY720 treatment of kidney transplant patients: a differential effect on B cells, naive T cells, memory T cells and NK cells, Transpl. Immunol. 15 (4) (2006) 281-288.

[186] T.A. Johnson, et al., Reduction of the peripheral blood CD56(bright) NK lymphocyte subset in FTY720-treated multiple sclerosis patients, J. Immunol. 187 (1) (2011) 570-579.

[187] M.C. Kowarik, et al., Differential effects of fingolimod (FTY720) on immune cells in the CSF and blood of patients with MS, Neurology 76 (14) (2011) 1214-1221.

[188] N. Collongues, et al., Pharmacotherapy for neuromyelitis optica Spectrum disorders: current management and future options, Drugs 79 (2) (2019) 125-142.

[189] M.M. Esiri, Immunoglobulin-containing cells in multiple-sclerosis plaques, Lancet 2 (8036) (1977) 478.

[190] B. Serafini, et al., Detection of ectopic B-cell follicles with germinal centers in the meninges of patients with secondary progressive multiple sclerosis, Brain Pathol. 14 (2) (2004) 164-174.

[191] X. Yu, et al., Intrathecally synthesized IgG in multiple sclerosis cerebrospinal fluid recognizes identical epitopes over time, J. Neuroimmunol. 240-241 (2011) 129-136.

[192] S.L. Hauser, et al., Ocrelizumab versus interferon Beta-1a in relapsing multiple sclerosis, N. Engl. J. Med. 376 (3) (2017) 221-234.

[193] L. Kappos, et al., Ocrelizumab in relapsing-remitting multiple sclerosis: a phase 2, randomised, placebo-controlled, multicentre trial, Lancet 378 (9805) (2011) $1779-1787$.

[194] X. Montalban, et al., Ocrelizumab versus placebo in primary progressive multiple sclerosis, N. Engl. J. Med. 376 (3) (2017) 209-220.

[195] P. Stashenko, et al., Characterization of a human B lymphocyte-specific antigen, J. Immunol. 125 (4) (1980) 1678-1685.

[196] P.J. Mease, B cell-targeted therapy in autoimmune disease: rationale, mechanisms, and clinical application, J. Rheumatol. 35 (7) (2008) 1245-1255.

[197] J.E. Holley, et al., CD20 + inflammatory T-cells are present in blood and brain of multiple sclerosis patients and can be selectively targeted for apoptotic elimination, Mult. Scler. Relat. Disord. 3 (5) (2014) 650-658. 